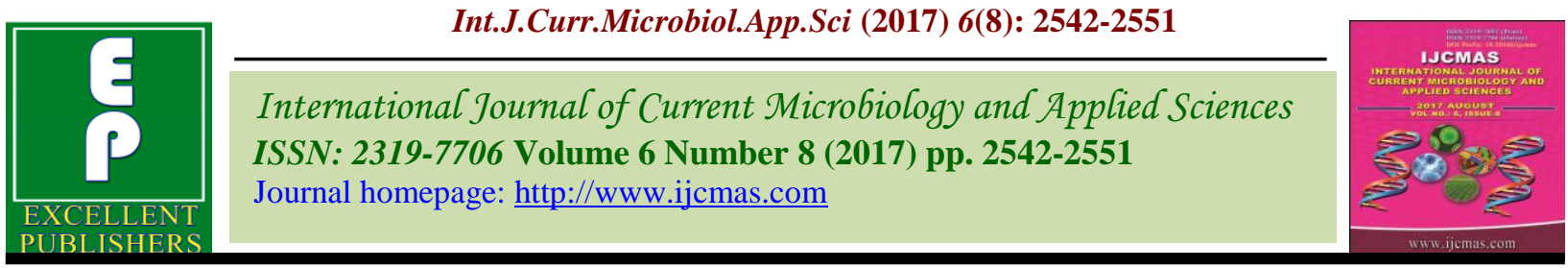

Original Research Article

https://doi.org/10.20546/ijcmas.2017.608.301

\title{
TH17/TH1 Role in Endocrine Disorders among Chronic HCV Infected Patients
}

\author{
Helal F. Hetta ${ }^{1 *}$, Azza Elkady $1^{2}$ and Ahmed Kh Meshaal ${ }^{3}$ \\ ${ }^{1}$ Department of Medical Microbiology and Immunology, Faculty of Medicine, \\ Assiut University, Assiut, Egypt \\ ${ }^{2}$ Sohag General Hospital, Sohag University, Sohag, Egypt \\ ${ }^{3}$ Department of Science, Al Azhar University, Assiut, Egypt \\ *Corresponding author
}

\section{A B S T R A C T}

\section{Keywords}

Th17, Th1, $H C V$, Endocrine disorders, Autoimmune disease.

Article Info

Accepted:

21 June 2017

Available Online:

10 August 2017
Since its discovery in 1989 , hepatitis C virus (HCV) infection has become a major cause of chronic liver disease worldwide with $14.7 \%$ prevalence in Egypt. There is increasing body of evidence that chronic HCV infection is usually associated with several extrahepatic manifestations. Several studies have shed light on the association of autoimmune thyroiditis (ATD) and type 1 diabetes (T1D) with chronic HCV infection as both are considered to be one of the most common organ specific autoimmune disease frequently occur together. IL17 secreting helper T (Th17) and classic Th1 cells have been heavily implicated in mediating autoimmune endocrine diseases. However, plasticity within this subset is suggested by the existence of IL-17 secreting cells, which are able to secrete interferon- $\gamma$, the signature pro-inflammatory cytokine for Th1 cells which named non-classic Th1 cells. Here in this review we will summarize the most common organ-specific autoimmune disease associated with chronic hepatitis $\mathrm{C}$ infection. Also, we will focus on the role of Th1 and Th17 cells in initiating the autoimmune reaction.

\section{Introduction}

Since its discovery in 1989, hepatitis C virus (HCV) has been considered as a major cause of chronic liver disease worldwide (Shepard et al., 2005).Egypt now has the highest prevalence of hepatitis $\mathrm{C}$ virus $(\mathrm{HCV})$ in the world, estimated nationally at $14.7 \%$ (Helal F. Hetta and Mohamed, 2017; Mehta et al., 2016; Mohamoud et al., 2013).Chronic hepatitis $\mathrm{C}$ is the most common cause of chronic liver disease and cirrhosis, and the most common indication for liver transplantation around the world. Hepatitis C virus is an RNA virus that belongs to the family flaviviridae (Chen and Morgan, 2006; Hetta, 2014). HCV is believed to be transmitted through large or repeated direct percutaneous exposures to blood (e.g., transfusion or transplantation from infectious donors, injecting drug use) (Shata et al., 2013; Soza et al., 2010). However, all the recent data suggest that although the liver is considered the major target organ, the virus 
may be able to replicate in peripheral blood mononuclear cells, lymph nodes and pancreas and to a more limited degree in bone marrow cells, thyroid, adrenal glands, and spleen (Gowans, 2000). It was reported that viral replication has been reported in B cells, $\mathrm{T}$ cells, monocytes, macrophages, and other macrophage-like cells such as Kupffer cells and dendrocytes (Hetta et al., 2015; Hetta et al., 2016; Revie and Salahuddin, 2011).

Chronic hepatitis $\mathrm{C}$ virus infection is usually associated with multiple extrahepatic manifestations affecting various organs in the body (Hetta et al., 2016; Ko et al., 2012). Autoimmune disease is considered to be one of the most common extrahepatic manifestation during hepatitis $\mathrm{C}$ infection. Autoimmunity and hepatitis $\mathrm{C}$ virus infection are closely related fields as it has been found that chronic HCV infection is associated with presence of circulating autoantibodies lymphoproliferative processes, and autoimmune (both systemic and organspecific) diseases (Ramos-Casals and Font, 2005).

Several studies have linked Th1 and Th17 immune response with $\mathrm{HCV}$ infection and endocrine disorders (Fallahi et al., 2012). Th1 and Th17 play an important role in mediating inflammatory process which in turn initiate the autoimmune reaction and autoantibodies production (Helal F. Hetta and Mohamed, 2017). Here in this review we will summarize the most common autoimmune endocrine disorders and we will shed light on the role of Th1and Th17 in mediating autoimmune endocrine disorders

HCV has been implicated both in the triggering of autoimmune diseases and in the development of autoantibodies. HCV might be involved in the breaking of tolerance to self-antigens and thus in triggering auto reactivity. Until recently, the association of
PEGylated interferon-alfa (IFN) with ribavirin was the gold-standard treatment for hepatitis C. PEG-IFN therapy may induce autoimmune disorders or worsen pre-existing autoimmune disorders. Therefore, it was important to screen autoantibodies prior to treatment; the diagnosis of an autoimmune disease may be a relative contraindication to IFN-based therapy (Narciso-Schiavon Jí and Schiavon, 2015).

During the last two decades, a considerable body of publications has appeared focusing on epitope mimicry as it was one of the most common suggested mechanism which provide the main argument for the hypothesis of autoimmunity among chronic HCV infection, while failing to provide conclusive evidence thus far (Fujinami et al., 2006). According to the hypothesis a susceptible individual acquires an infection with an agent, the connection between autoimmunity and infection is two-fold: molecular mimicry can act as a direct mechanism for inducing autoimmunity, and the indirect activation of auto reactive $\mathrm{B}$ - and $\mathrm{T}$-Lymphocytes in the event of an infection can result in autoimmunity. Much has been learned regarding these mechanisms in animal models (Strassburg et al., 2003).

\section{HCV-related autoimmune endocrine disorders}

HCV has been implicated both in the triggering of autoimmune diseases and in the development of autoantibodies. Autoimmune diseases associated with $\mathrm{HCV}$ infection are described under two broad categories; organspecific autoimmune diseases and systemic autoimmune diseases. In organ-specific autoimmune diseases, the autoimmune responses, autoantibodies are directed against self- antigens present only in a particular organ which lead to destruction of $\beta$-cells (Lesage and Goodnow, 2001). Replication of 
HCV in thyroid cells and pancreatic islet cells will initiate autoimmune reaction through presentation of pancreatic cell antigen and thyroid antigen to antigen presenting cells (APC) as shown in figure 1.

\section{Autoimmune thyroid disease}

Several investigations propose a potential association between $\mathrm{HCV}$ infection and autoimmune thyroiditis (AT) (Helal F. Hetta and Mohamed, 2017). Ganne -carrie et al., suggested that $\mathrm{AT}$ is more frequent in patients with chronic HCV infection than in noninfected patients (Ganne-Carrie et al., 2000). In their study, the overall prevalence of thyroid abnormalities was higher in $\mathrm{HCV}$ infected patients than in controls (17\% vs. $4 \%$ ). The prevalence of anti-thyroid antibodies, anti-microsomal or antithyroperoxidase antibodies was higher in patients with chronic hepatitis $\mathrm{C}$ before IFN therapy. The prevalence of abnormal concentrations of anti-thyroid antibodies in patients with chronic HCV differed prominently, ranging from $2 \%$ to $48 \%$. Furthermore, a high prevalence of anti HCV antibodies in patients with anti-thyroid antibodies and in patients with AT has been detected, although this finding was not confirmed in all studies (Ganne-Carrie et al., 2000). Thyroid dysfunction may present in different forms such as Graves' disease (GD) and Hashimoto's thyroiditis (HT) which are also the most common causes of autoimmune thyroid diseases. Nonetheless, two main hypotheses are proposed: primary cytopathic effect of virus and secondary-induced autoimmunity. It has been suggested that virological features of $\mathrm{HCV}$, may influence progression of thyroid autoimmune disease through mechanisms such as molecular mimicry (Testa et al., 2006). Other studies show that Patients with chronic HCV infection were more likely to have hypothyroidism (13\%), antithyroglobulin antibodies ( $\mathrm{TgAb}, 17 \%)$ and antithyroperoxidase antibodies (TPOAb, 21\%) than individuals in any of the control groups (Pateron et al., 1992).

\section{Autoimmune diabetes}

Diabetes mellitus type 1 , formerly known as insulin-dependent diabetes or juvenile diabetes, it is characterized by immunemediated destruction of pancreatic $\beta$-cells consequent with interactions between genetic susceptibility and environmental factors and considered one of endocrine related disorders among chronic HCV patients (Tosone et al., 2013).

The patient becomes symptomatic only when about $80 \%$ of $\beta$ cells are destroyed. The affected patients by T1DM tested positive to antibodies against islet cells (ICA), insulin (IAA), glutamic acid decarboxylase (GADA), tyrosine phosphatase (IA-2) and zinc transporter 8 (ZnT8) at the time of diagnosis. The diagnostic specificity of GADA, IAA, IA-2 and ZnT8 is 99\%; GADA has the highest diagnostic sensitivity, namely 70$90 \%$. Besides their diagnostic value, pancreatic autoantibodies could help to identify people with an increased risk for developing the disease, particularly the firstdegree relatives of diabetic patients (Masuda et al., 2007).

Yan F et al., has proved in his study that $\mathrm{HCV}$ RNA and HCV replicative intermediate in kidney, heart, pancreas, and intestine were detected by RT-PCR, but more importantly, the localization of $\mathrm{HCV}$ RNA and $\mathrm{HCV}$ antigens (NS3, NS5 and CP10) in pancreas acinar cells were also identified (Yan et al., 2000). Conversely, it is plausible that HCV infection may cause pancreatic islet dysfunction and/or trigger islet autoimmunity. Interestingly, epidemiological studies have shown a strong relationship between hepatitis 
$\mathrm{C}$ and pancreatic carcinoma, also suggesting direct infection of the pancreas by $\mathrm{HCV}$ and induction of local inflammation If indeed direct infection of islets or acinar cells by $\mathrm{HCV}$ is confirmed (Hammerstad et al., 2015), as it can trigger autoimmunity in susceptible individuals by inducing local inflammation with cytokine and chemokine secretion (also called "bystander mechanism
(Helal F. Hetta, 2017). Epidemiological studies have suggested but not confirmed an association between HCV infection and islet autoimmunity. However in several studies, the frequency of T1D autoantibodies were not significantly higher in chronic $\mathrm{HCV}$-infected patients selected for IFN $\alpha$ therapy than that in controls (Fabris et al., 2003).

Fig.1 Role of TH1, TH17 and TH17/TH1 in mediating organ specific autoimmune disorder associated with HCV infection

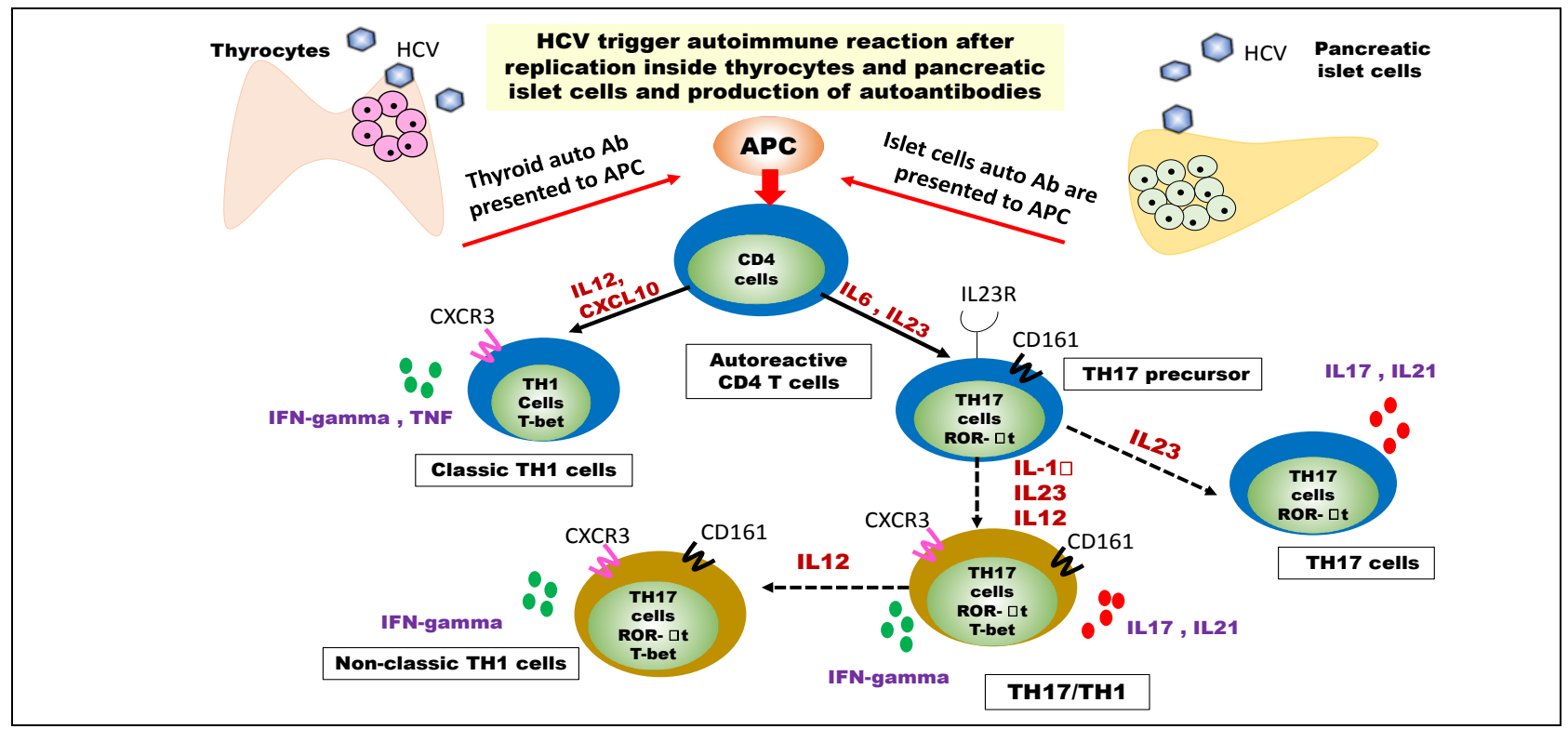

Replication of HCV in thyroid cells and pancreatic islet cells will initiate autoimmune reaction through presentation of pancreatic cell antigen and thyroid antigen to antigen presenting cells (APC). Autoreactive CD4 T cell will drive TH1 and TH17 which is governed by certain cytokines and transcription factors. However, the IL17 producing TH17 cells in the presence of IL-1 $\beta$ and IL-23, TH17 precursors differentiate into mature Th17 cells capable of IL-17A production. In the presence of IL-23, the Th17 phenotype is maintained as seen with the preservation of all surface markers, IL-17A and ROR $\gamma \mathrm{t}$. When cultured with IL-12, however, mature Th17 cells adopt a divergent phenotype that has both Th1 and Th17-like aspects, termed Th1/Th17 cells, express CXCR3 produce both IFN- $\gamma$ as well as IL-17A, and have a high expression of ROR $\gamma \mathrm{t}$ with an intermediate expression of the Th1 transcription factor, T-bet. In the continued presence of IL-12, Th1/Th17 cells can adopt a Th1-like phenotype and are termed non-classical Th1 cells. As shown, non-classical Th1 cells have an increased expression of T-bet, decreased ROR $\gamma \mathrm{t}$, and produce only IFN- $\gamma$. (B) Classical Th1 cells are directly derived from naïve CD4+ T cells in the presence of IL-12 and can be identified through the expression of CXCR3, IFN- $\gamma$, and T-bet. The proinflammatory cytokines produced by TH1 (classic and nonclassic) and TH17 will in turn initiate inflammatory process and autoimmune response in target organs (pancreatic islet cells and thyroid gland) 
Recent Epidemiological data have shown that T1D and AITD frequently occur together in the same family and in the same individual, suggesting a strong shared genetic susceptibility. In different studies, up to $44 \%$ of T1D patients were positive for thyroid antibodies, including; (thyroid peroxidase (TPO) and/or thyroglobulin (Tg) antibodies).Indeed, the co-occurrence of T1D and AITD in the same individual is classified as one of the variants of autoimmune polyglandular syndrome type 3 (APS3). (Tomer et al., 2015) This results suggesting a significant shared genetic susceptibility (Hansen et al., 2015).

\section{Role of TH1 and TH17 in Organ-specific autoimmune disease among Chronic $\mathrm{HCV}$}

Although few serological studies have performed on the possible association of thyroid autoantibodies and T1D autoantibodies in $\mathrm{HCV}$-infected patients, Many studies have linked Th1 and Th17 immune response with $\mathrm{HCV}$ infection and endocrine disorders (Fallahi et al., 2012). Based on their effector cytokines they can exert their proinflammatory response. As shown in figure $1, \mathrm{HCV}$ infection may act by up regulating CXCL10secretion by both thyrocytes and beta-cells; this chemokine is responsible for Th1 lymphocyte recruitment. The production of IFN $\gamma$ and TNF $\alpha$ enhances CXCL10 secretion by target glandular cells, thus perpetuating the immune cascade. Several studies have shown an increased expression of interferon-gamma (IFN $\gamma$ ), and IFN $\gamma$ inducible chemokines (overall CXCL10), in hepatocytes and in lymphocytes of $\mathrm{HCV}$-infected patients, directly related with the degree of inflammation and with an increase of circulating levels of IFN $\gamma$ and CXCL10. Moreover, two recent studies suggest that high plasma concentrations of CXCL10 may be a predictor of unresponsiveness to antiviral therapy with interferon- $\alpha$ with or without ribavirin in $\mathrm{HCV}$ chronic infection. These data suggest that CXCL10 produced by HCV-infected hepatocytes could play a key role regulating T-cell trafficking into a Th1-type inflammatory site (as it is the liver tissue during chronic $\mathrm{HCV}$ infection) by recruiting Th1 lymphocytes, that secrete IFN $\gamma$ and TNFa, which has synergistic effect on CXCL10 secretion by hepatocytes, thus perpetuating the immune response (Apolinario et al., 2005).

The infection of beta-cells by $\mathrm{HCV}$ might induce an inflammatory or autoimmune reaction (Abdel-Hameed et al., 2016). Furthermore, our preliminary data show that IFN $\gamma$ and TNF $\alpha$ stimulate CXCL10 secretion in beta-cells, and that this process can be inhibited by PPAR-gamma and PPAR-alpha agonists. Furthermore, IFN $\alpha$ and IFN $\beta$ stimulate CXCL10 secretion in beta-cells, similarly to that observed with IFN $\gamma$. On the above mentioned bases, it could be interesting to speculate that $\mathrm{HCV}$ infection of beta-cells may act by up regulating CXCL10 gene expression and secretion (as previously shown in human hepatocytes, recruiting Th1 lymphocytes, that secrete IFN $\gamma$ and TNF $\alpha$, that induce CXCL10 secretion by beta-cells, thus perpetuating the immune cascade, that may lead to the appearance of beta-cells dysfunction in genetically predisposed subjects (Masini et al., 2005).The net result of TH1 immune response is elevation of IFN gamma in the area of inflammation (Damsker et al., 2010).

Recently, a novel subset of Th, cells which is distinct from Th1 and Th2, and is called Th17, has been described. Th17 cells are characterized by the ability to secrete IL-17A, IL-17F, IL-21, IL-22, and IL-6. The ubiquitous expression of IL-17 receptors means that it can act on a broad range of cellular targets. IL-17A and IL-17F function 
primarily as proinflammatory mediators, inducing local production of IL-6, prostaglandin $\mathrm{E}_{2}$, and nitric oxide, and specifically recruiting neutrophils (Balanescu et al., 2012). Although important progress has been made in these areas, the participation of Th17 cells in HCV chronic infection has not been well characterized and has been documented in only a few recent studies, Th 17 cytokines have been described as an important mediator in autoimmune disease (Sousa et al., 2012).IL-17 is a powerful chemoattractant for neutrophils and has been reported to be involved in many immune processes, most notably in inducing and mediating proinflammatory responses. (Hassan et al., 2014)

Recent studies show that Th17 play a major role in exacerbates proinflammatory chemokine expression and secretion by human islets exposed to cytokines. This suggests that IL-17A contributes to the pathogenesis of type 1 diabetes by two mechanisms, namely the exacerbation of beta cell apoptosis and increased local production of chemokines, thus potentially aggravating insulitis.

CXCL10 and CXCL9 are present in pancreatic islets from type 1 diabetic patients, while infiltrating lymphocytes express the CXCL10 receptor, C-X-C chemokine receptor type 3 , suggesting a 'dialogue' between chemokine-producing islet cells and the invading immune cells. In NOD mice, the severity of insulitis is reduced in IL-17- or IL$17 / \mathrm{IFN}-\gamma$ receptor-deficient animals, indicating the importance of IL-17A in the attraction of immune cells.

(Grieco et al., 2014) On the other hand,TH17 increase upregulation of CXCL10 which is also expressed by thyroid cell leading to autoimmune thyroiditis (González-Amaro and Marazuela, 2015).
TH1/TH17 plasticity role in autoimmune disease

There is some evidence of the role of T-cell plasticity in autoimmune endocrine disorders. Recent studies suggest that the development of Th17 cells secreting both IFN- $\gamma$ and IL-17 seems to associate with impaired $\beta$ cell function and progression to overt type 1 diabetes in autoantibody-positive individuals. It has been suggested that the degree of Th1/Th17 plasticity could be a novel biomarker for disease progression and accelerated destruction of the insulinproducing cells in children with $\beta$ cell autoimmunity. Further support the association of Th1/Th17 cells and impaired $\beta$ cell function in human type 1 diabetes. It is possible that Th17 cells co-secreting IFN- $\gamma$ and IL-17 are detrimental to $\beta$ cells and mediate aggressive $\beta$ cell destruction as indicated by in vitro studies showing an additive effect of IFN- $\gamma$ and IL-17 on $\beta$ cell apoptosis (Reinert-Hartwall et al., 2015).

The plasticity of TH17 allow rapid shift into TH1 phenotype. The cells which produce IFN- $\gamma$ and IL17a together was named Th17/Th1 cells (Duhen and Campbell, 2014).It was shown that human Th17 cells can also be shifted to the non- classic Th1 phenotype in the presence of tumor necrosis factor- $\alpha$ (TNF- $\alpha)$, IL12. Moreover, repeated stimulation of Th17 cells in the presence of IL-23 can directly up-regulate IFN$\gamma$ independently of T-bet. IL- $1 \beta$ as a key cytokine that renders Th17 cells sensitive to IL-12, and both cytokines together potently induced the differentiation of cells that produce IL-17 and IFN- $\gamma$ and the contemporary production of these cytokines has been associated with pathogenicity in autoimmune diseases (Duhen and Campbell, 2014).This shift may alter the cytokines profile in thyroid gland, leading to autoimmune thyroiditis (Annunziato et al., 
2015). Th17-derived Th1, named non-classic Th1, can be easily distinguished from classic Th1 cells on the basis of CD161 expression as well as the consistent expression of RORC, IL-17 receptor E, CCR6 and IL-4-induced gene 1 which are all virtually absent in classic Th1 cells (Annunziato et al., 2007).

In conclusion, there is a strong association between organ specific autoimmune diseases and chronic HCV infection. However, few serological studies have performed on the possible suggested mechanisms of thyroid autoantibodies and T1D autoantibodies in $\mathrm{HCV}$-infected patients. On the other hand, many studies have linked Th1 and Th17 immune response with $\mathrm{HCV}$ infection and endocrine disorders. Also, the high plasticity of Th17 cell which is rapidly shift to nonclassic Th1 cell and associated with high production of pro-inflammatory cytokines as IL17 and IFN-gamma could be responsible for initiating the autoimmune reaction among chronic HCV infection.

\section{Abbreviations}

HCV: Hepatitis C Virus; IFN: interferon; Th: $\mathrm{T}$ helper; AT: autoimmune thyroiditis; DM: Diabetes Mellitus; TPO: thyroid peroxidase; IFN- $\gamma$, Interferon gamma; ANA, Antinuclear antibody; IL, Interleukin.

\section{Acknowledgement}

We thank the Grant office, Faculty of Medicine, Assiut University, Egypt for their financial support.

\section{References}

Abdel-Hameed, E. A., Rouster, S. D., Ji, H., Ulm, A., Hetta, H. F., Anwar, N., Sherman, K. E. and Shata, M. T. (2016). Evaluating the Role of Cellular Immune Responses in the Emergence of $\mathrm{HCV}$
NS3 Resistance Mutations During Protease Inhibitor Therapy. Viral immunology29, 252-258.

Annunziato, F., Cosmi, L., Liotta, F., Maggi, E. and Romagnani, S. (2015). Human T helper type 1 dichotomy: origin, phenotype and biological activities. Immunology144, 343-351.

Annunziato, F., Cosmi, L., Santarlasci, V., Maggi, L., Liotta, F., Mazzinghi, B., Parente, E., Fili, L., Ferri, S. and other authors (2007). Phenotypic and functional features of human Th17 cells. $J$ Exp Med204, 1849-1861.

Apolinario, A., Majano, P. L., Lorente, R., Nunez, O., Clemente, G. and GarciaMonzon, C. (2005). Gene expression profile of T-cell-specific chemokines in human hepatocyte-derived cells: evidence for a synergistic inducer effect of cytokines and hepatitis $\mathrm{C}$ virus proteins. J Viral Hepat12, 27-37.

Balanescu, P., Ladaru, A., Voiosu, T., Nicolau, A., Ene, M. and Balanescu, E. (2012). Th17 and IL-17 immunity in chronic hepatitis C infection. Rom $J$ Intern Med50, 13-18.

Chen, S. L. and Morgan, T. R. (2006). The natural history of hepatitis $\mathrm{C}$ virus (HCV) infection. Int J Med Sci3, 47-52.

Damsker, J. M., Hansen, A. M. and Caspi, R. R. (2010). Th1 and Th17 cells: Adversaries and collaborators. Ann NY Acad Sci1183, 211-221.

Duhen, T. and Campbell, D. J. (2014). IL1beta promotes the differentiation of polyfunctional human CCR6+CXCR3+ Th1/17 cells that are specific for pathogenic and commensal microbes. Journal of immunology (Baltimore, Md : 1950)193, 120-129.

Fabris, P., Floreani, A., Tositti, G., Vergani, D., De Lalla, F. and Betterle, C. (2003). Type 1 diabetes mellitus in patients with chronic hepatitis $\mathrm{C}$ before and after interferon therapy. Alimentary 
pharmacology and therapeutics 18,549 558.

Fallahi, P., Ferri, C., Ferrari, S. M., Corrado, A., Sansonno, D. and Antonelli, A. (2012). Cytokines and HCV-related disorders. Clinical and Developmental Immunology2012.

Fujinami, R. S., von Herrath, M. G., Christen, U. and Whitton, J. L. (2006). Molecular Mimicry, Bystander Activation, or Viral Persistence: Infections and Autoimmune Disease. Clinical Microbiology Reviews 19, 80-94.

Ganne-Carrie, N., Medini, A., Coderc, E., Seror, O., Christidis, C., Grimbert, S., Trinchet, J. C. and Beaugrand, M. (2000). Latent autoimmune thyroiditis in untreated patients with $\mathrm{HCV}$ chronic hepatitis: a case-control study. Journal of autoimmunity 14, 189-193.

González-Amaro, R. and Marazuela, M. (2015). $\mathrm{T}$ regulatory (Treg) and $\mathrm{T}$ helper 17 (Th17) lymphocytes in thyroid autoimmunity. Endocrine, 1-9.

Gowans, E. J. (2000). Distribution of markers of hepatitis $\mathrm{C}$ virus infection throughout the body. Semin Liver Dis20, 85-102.

Grieco, F. A., Moore, F., Vigneron, F., Santin, I., Villate, O., Marselli, L., Rondas, D., Korf, H., Overbergh, L. and other authors (2014). IL-17A increases the expression of proinflammatory chemokines in human pancreatic islets. Diabetologia57, 502-511.

Hammerstad, S. S., Grock, S. F., Lee, H. J., Hasham, A., Sundaram, N. and Tomer, Y. (2015). Diabetes and Hepatitis C: A Two-Way Association. Frontiers in endocrinology6, 134.

Hansen, M. P., Matheis, N. and Kahaly, G. J. (2015). Type 1 diabetes and polyglandular autoimmune syndrome: A review. World Journal of Diabetes6, 67-79.

Hassan, E. A., El, A. S. E.-D. A., Rehim, A. O. A., Elsherbiny, N. M. and Elhagag,
N. A. E.-R. A. (2014). The Impact of Serum Interleukin-17 on Chronic Hepatitis C and Its Sequelae. Journal of Liver2014.

Helal F. Hetta, A. E., Khairy H. Morsy, Ismael S. Mohamed (2017). Serum Level of IL17a among Cirrhotic Hepatitis C Virus Infected Patients with Incidence of Diabetes Mellitus. THE EGYPTIAN JOURNAL OF IMMUNOLOGY24.

Helal F. Hetta, A. E., Khairy H. Morsy, Ismail S Mohamed, Khaled M. Hassanein, Tohamy A. Tohamy, Hala M. ElBadre and Mohamed, G. A. (2017). Circulating IL17a and IFN-Gamma Serum Levels in Cirrhotic Hepatitis C Virus Infected Patients with Autoimmune Thyroiditis. International Journal of Current Microbiology and Applied Sciences6, 1972-1983.

Hetta, H. F. (2014). Gut immune response in the presence of hepatitis $\mathrm{C}$ virus infection. World Journal of Immunology4, 52.

Hetta, H. F., Mekky, M. A., Khalil, N. K., Mohamed, W. A., El-Feky, M. A., Ahmed, S. H., Daef, E. A., Nassar, M. I., Medhat, A. and other authors (2015). Association of colonic regulatory $\mathrm{T}$ cells with hepatitis $\mathrm{C}$ virus pathogenesis and liver pathology. Journal of gastroenterology and hepatology30, 1543-1551.

Hetta, H. F., Mekky, M. A., Khalil, N. K., Mohamed, W. A., El-Feky, M. A., Ahmed, S. H., Daef, E. A., Medhat, A., Nassar, M. I. and other authors (2016). Extra-hepatic infection of hepatitis $\mathrm{C}$ virus in the colon tissue and its relationship with hepatitis $\mathrm{C}$ virus pathogenesis. Journal of medical microbiology65, 703-712.

Ko, H. M., Hernandez-Prera, J. C., Zhu, H., Dikman, S. H., Sidhu, H. K., Ward, S. C. and Thung, S. N. (2012). 
Morphologic Features of Extrahepatic Manifestations of Hepatitis C Virus Infection. Clinical and Developmental Immunology2012, 9 .

Lesage, S. and Goodnow, C. C. (2001). Organ-Specific Autoimmune Disease: A Deficiency of Tolerogenic Stimulation. The Journal of Experimental Medicine194, f31-36.

Masini, M., Campani, D., Boggi, U., Menicagli, M., Funel, N., Pollera, M., Lupi, R., Del Guerra, S., Bugliani, M. and other authors (2005). Hepatitis C virus infection and human pancreatic $\beta$ cell dysfunction. Diabetes care 28, 940941.

Masuda, H., Atsumi, T., Fujisaku, A., Shimizu, C., Yoshioka, N. and Koike, T. (2007). Acute onset of type 1 diabetes accompanied by acute hepatitis $\mathrm{C}$ : the potential role of proinflammatory cytokine in the pathogenesis of autoimmune diabetes. Diabetes Res Clin Pract75, 357-361.

Mehta, M., Hetta, H. F., Abdel-Hameed, E. A., Rouster, S. D., Hossain, M., Mekky, M. A., Khalil, N. K., Mohamed, W. A., El-Feky, M. A. and other authors (2016). Association between IL28B rs12979860 single nucleotide polymorphism and the frequency of colonic Treg in chronically $\mathrm{HCV}$ infected patients. Archives of virology161, 3161-3169.

Mohamoud, Y. A., Mumtaz, G. R., Riome, S., Miller, D. and Abu-Raddad, L. J. (2013). The epidemiology of hepatitis C virus in Egypt: a systematic review and data synthesis. BMC Infect Dis13, 288.

Narciso-Schiavon Jí, L. and Schiavon, L. L. (2015). Autoantibodies in chronic hepatitis C: A clinical perspective. World J Hepatol7, 1074-1085.

Pateron, D., Hartmann, D. J., Duclos-Vallee, J. C., Jouanolle, H. and Beaugrand, M. (1992). Latent autoimmune thyroid disease in patients with chronic $\mathrm{HCV}$ hepatitis. J Hepatol 16, 244-245.

Ramos-Casals, M. and Font, J. (2005). Extrahepatic manifestations in patients with chronic hepatitis $\mathrm{C}$ virus infection. Current opinion in rheumatology17, $447-455$.

Reinert-Hartwall, L., Honkanen, J., Salo, H. M., Nieminen, J. K., Luopajärvi, K., Härkönen, T., Veijola, R., Simell, O., Ilonen, J. and other authors (2015). Th1/Th17 Plasticity Is a Marker of Advanced $\beta$ Cell Autoimmunity and Impaired Glucose Tolerance in Humans. J Immunol194, 68-75.

Revie, D. and Salahuddin, S. Z. (2011). Human cell types important for Hepatitis C Virus replication in vivo and in vitro. Old assertions and current evidence. Virol J8, 346.

Shata, M. T., Abdel-Hameed, E. A., Hetta, H. F. and Sherman, K. E. (2013). Immune activation in HIV/HCV-infected patients is associated with low-level expression of liver expressed antimicrobial peptide-2 (LEAP-2). Journal of clinical pathology66, 967975.

Shepard, C. W., Finelli, L. and Alter, M. J. (2005). Global epidemiology of hepatitis $\mathrm{C}$ virus infection. The Lancet infectious diseases5, 558-567.

Sousa, G. M., Oliveira, I. S., Andrade, L. J., Sousa-Atta, M. L., Parana, R. and Atta, A. M. (2012). Serum levels of Th17 associated cytokines in chronic hepatitis C virus infection. Cytokine60, 138-142.

Soza, A., Riquelme, A. and Arrese, M. (2010). Routes of transmission of hepatitis C virus. Annals of hepatology9 Suppl, 33.

Strassburg, C. P., Vogel, A. and Manns, M. P. (2003). Autoimmunity and hepatitis C. Autoimmunity reviews2, 322-331.

Testa, A., Castaldi, P., Fant, V., Fiore, G. F., Grieco, V., De Rosa, A., Pazardjiklian, 
M. G. and De Rosa, G. (2006). Prevalence of $\mathrm{HCV}$ antibodies in autoimmune thyroid disease. Eur Rev Med Pharmacol Sci10, 183-186.

Tomer, Y., Dolan, L. M., Kahaly, G., Divers, J., D'Agostino, R. B., Jr., Imperatore, G., Dabelea, D., Marcovina, S., Black, M. H. and other authors (2015). Genome wide identification of new genes and pathways in patients with both autoimmune thyroiditis and type 1 diabetes. Journal of autoimmunity60, 32-39.
Tosone, G., Maraolo, A. E., Palmiero, G., Mascolo, S. and Orlando, R. (2013). Diabetes Mellitus Type 1, Latent Autoimmune Diabetes of Adults and Hepatitis C Virus: What we Know and what we Need to Know. J Diabetes Metab4, 2.

Yan, F. M., Chen, A. S., Hao, F., Zhao, X. P., Gu, C. H., Zhao, L. B., Yang, D. L. and Hao, L. J. (2000). Hepatitis C virus may infect extrahepatic tissues in patients with hepatitis C. World Journal of Gastroenterology6, 805-811.

\section{How to cite this article:}

Helal F. Hetta, Azza Elkady and Ahmed Kh Meshaal. 2017. TH17/TH1 Role in Endocrine Disorders among Chronic HCV Infected Patients. Int.J.Curr.Microbiol.App.Sci. 6 (8): 25422551. doi: https://doi.org/10.20546/ijcmas.2017.608.301 